\title{
As estações de Marcovaldo: relação entre cidade e natureza a partir da obra Marcovaldo ou As estações na cidade, de Italo Calvino
}

\section{Bruna Fontes Ferraz ${ }^{1}$ (UFMG)}

Resumo: Neste ensaio, pretendemos refletir sobre a relação entre o homem urbano, a natureza e os novos valores instaurados pela modernidade bem como sobre as consequências da modernização a partir de discussões levantadas pelo filósofo alemão Walter Benjamin e do texto literário Marcovaldo ou As estações na cidade (1963), de Italo Calvino.

Palavras-chave: Modernidade; Natureza; Cidade.

\footnotetext{
"O vento, vindo de longe para a cidade, oferece a ela dons insólitos, dos quais se dão conta somente poucas almas sensíveis." Italo Calvino, Marcovaldo ou As estações na cidade.
}

A cidade, como símbolo essencial da modernização, bem como os problemas ocasionados por uma civilização industrial são temas recorrentes da literatura neorealista, principalmente porque na literatura do pós-guerra "já não se denuncia tanto a miséria, mas um mundo em que todos os valores se tornam mercadorias para vender e comprar, no qual há o perigo de se perder o sentido da diferença entre as coisas e os seres humanos, e tudo é avaliado em termos de produção e consumo." (CALVINO, 1994, p. 142). Essa problematização resultante da modernidade é tema comum não só de textos literários como também de discussões teóricas e filosóficas, já que o advento da modernidade não questiona somente a vida contemporânea mas também as consequências desse processo de modernização. É pensando, pois, nessa relação entre o homem urbano, a natureza e os novos valores instaurados pela modernidade que propomos aqui refletir sobre as consequências da modernização num encontro/confronto entre o pensamento do filósofo alemão Walter Benjamin e as aventuras/desventuras do personagem Marcovaldo no livro Marcovaldo ou As estações na cidade (1963), de Italo Calvino.

A crítica de Benjamin (1994) se dirige ao fato de que as pessoas, na modernidade industrializada, vêm perdendo a capacidade de se comunicar e de relatar suas experiências. Na cidade, nas cidades grandes - lugar da industrialização, do consumo sem retorno - não há espaço para que as experiências se manifestem, pois com a especulação imobiliária os espaços da memória da cidade vão sendo substituídos por prédios - construções sem identidade, sem aura, sem tradição. Além disso, com a modernização instaura-se, nas cidades, um ritmo acelerado, já que as pessoas dizem não ter tempo. Assim, se a tradição repousa em objetos preservados tanto pelo espaço quanto pelo tempo, a aura é "composta de elementos espaciais e temporais" (BENJAMIN, 1994,

Cadernos Benjaminianos, n. 3, Belo Horizonte, jan.-jun. 2011, p.34-42 
p. 170). Para o filósofo alemão os movimentos de massa buscam a proximidade das obras de arte através de sua reprodução, o que tem ocasionado a perda da aura.

Concomitantemente à perda da aura, citando Simmel, Benjamin considera que na cidade grande há uma preponderância da atividade visual sobre a auditiva (na cidade se vê mais que se fala e se ouve).

Quem vê sem ouvir fica muito mais inquieto do que quem ouve sem ver. Eis algo característico da sociologia da cidade grande. As relações recíprocas dos seres humanos nas cidades se distinguem por uma notória preponderância da atividade visual sobre a auditiva. Suas causas principais são os meios públicos de transporte. Antes do desenvolvimento dos ônibus, dos trens, dos bondes no século XIX, as pessoas não conheciam a situação de terem de se olhar reciprocamente por minutos, ou mesmo por horas a fio, sem dirigir a palavra umas às outras. (BENJAMIN, 1995, p. 36)

Em contraposição a essa crise da comunicação, Benjamin destaca a figura do narrador como depositário e transmissor das experiências e da tradição, pois, a seu ver, a narração pode se basear ou na figura do camponês sedentário que nunca saiu de sua terra e que conhece suas tradições, lendas, histórias, ou seja, aquele que supera grandes distâncias temporais; ou na figura do marinheiro comerciante que viaja para os mais diversos lugares, isto é, aquele que supera grandes distâncias espaciais. Desse modo, para Benjamin a figura do artesão sintetizaria tanto o camponês sedentário quanto o marinheiro comerciante. (BENJAMIN, 1994, p. 198-199).

No entanto, na Modernidade a falta de experiências vividas ou aprendidas ou apreendidas tem gerado uma crise na capacidade de narrar que poria em risco a transmissão da memória e da tradição, porque essa transmissão se mantém, se propaga, se difunde pela narração, a qual se baseia na "faculdade de intercambiar experiências" (BENJAMIN, 1994, p. 198). Para o filósofo alemão, a transmissão das experiências é um modo de resistir contra o esquecimento.

A crise do relato de experiências - com o gradual, perigoso desaparecimento da figura do narrador - e o apagamento da memória cultural e arquitetônica não seriam as únicas consequências da modernização: para Benjamin, a reprodução da obra de arte, mesmo a reprodução mais perfeita, que seria aquela feita manualmente, teria um elemento ausente: "o aqui e agora da obra de arte, sua existência única, no lugar em que ela se encontra" (BENJAMIN, 1994, p. 167). A reprodução desvaloriza, portanto, o aqui e agora da obra, ou seja, sua aura, eliminando a sua singularidade, ou seja, "o que se atrofia na era da reprodutibilidade técnica da obra de arte é sua aura" (BENJAMIN, 1994, p. 168).

Nesse sentido, com a perda da autenticidade, da aura da obra de arte, a função social da arte deixa de ser sagrada, religiosa e passa a ser política. Com esse caráter político, o valor de exposição da obra de arte aumenta. Benjamin, então, opõe o "valor de exposição" ao "valor de culto", sendo que este está a serviço da magia - pela existência única da obra de arte -, enquanto aquele se refere ao fato de a obra, devido à sua multiplicação, à sua existência serial, ficar mais exposta.

Desse modo, percebemos que tanto a reprodução técnica, mecânica da obra de arte, quanto a perda da memória da cidade, no âmbito urbano - por não cultivarem suas tradições, suas auras - acarretam em uma ilusão, já que a cidade ao mesmo tempo que destrói as manifestações da arte e da natureza, procura recriá-las, mesmo que artificialmente. A definição do filósofo alemão para a aura remete à natureza enquanto

Cadernos Benjaminianos, n. 3, Belo Horizonte, jan.-jun. 2011, p.34-42 
ambiente integrador, em oposição à modernidade, em que a natureza é artificialmente conservada em forma de parques, praças, etc., confirmando, de certa maneira, a desintegração generalizada. Benjamin não questiona a aura e a tradição no mundo prémoderno de "O Narrador", mas considera o culto a objetos singulares como inadequado à realidade moderna, em que nada mais seria singular / autêntico / único, etc.

Esse embate entre o natural e o artificial faz da cidade

parte da fantasmagoria da modernidade, enquanto locus eminente dos seus mitos. Os edifícios e os objetos da metrópole são imagens de sonho por que representam aspirações jamais concluídas. A fantasmagoria urbana apresenta, assim, sua dualidade: tanto é utopia quanto cinismo - espaço da frustração, da inversão e distorção dos sonhos. (VELLOSO, 2010, p. 4).

Assim, como um meio de reagir à frustração e ao ritmo da cidade grande, em seus ensaios sobre o poeta francês Charles Baudelaire, Benjamin vislumbra a figura do flâneur, um ser que, anônimo, opondo-se ao trabalho, estranho à realidade da cidade, vaga por ela para ser tanto seu crítico quanto seu arauto.

Benjamin comenta que antes do flâneur de Baudelaire havia uma série de livros chamados fisiológicos que tratavam de algum aspecto da cidade ou de seus moradores sempre com uma visão inofensiva, algo idílico que não condizia com a real situação das cidades com suas diferenças sociais, suas misérias, etc. Contudo, com o surgimento do flâneur, sua presença passa a ser justamente uma forma de revelar o caos, a incoerência e as injustiças da cidade, pois

desse modo, se o flâneur se torna sem querer detetive, socialmente a transformação lhe assenta muito bem, pois justifica a sua ociosidade. Sua indolência é apenas aparente. Nela se esconde a vigilância de um observador que não perde de vista o malfeitor. Assim, o detetive vê abrirem-se à sua autoestima vastos domínios. Desenvolve formas de reagir convenientes ao ritmo da cidade grande. Capta as coisas em pleno voo, podendo assim imaginar-se próximo ao artista. Todos elogiam o lápis veloz do desenhista. (BENJAMIN, 1995, p. 38)

No entanto, para Benjamin, o flâneur de Baudelaire, por procurar prazer na cidade, torna-se também uma mercadoria para o consumo de seus clientes, quer sejam eles leitores ou espectadores. Assim,

o flâneur é um abandonado na multidão. Com isso, partilha a situação da mercadoria. Não está consciente dessa situação particular, mas nem por isso ela age menos sobre ele. Penetra-o como um narcótico que o indeniza por muitas humilhações. A ebriedade a que se entrega o flâneur é a da mercadoria em torno da qual brame a corrente dos fregueses. (BENJAMIN, 1995, p. 51-52)

É nesse espaço de "inversão e distorção de sonhos", de mercantilização e reificação que se passa a obra Marcovaldo ou As estações na cidade, de Italo Calvino, em que através do personagem Marcovaldo o leitor é levado, convidado a flanar por uma cidade anônima, industrializada e labiríntica. A cidade não é apenas pano de fundo das

Cadernos Benjaminianos, n. 3, Belo Horizonte, jan.-jun. 2011, p.34-42 
aventuras/desventuras de Marcovaldo, pois ela se contrasta e se sobrepõe a uma natureza perdida e destruída.

Primavera, verão, outono e inverno, em torno dos quais os vinte contos são agrupados, definem cada uma das aventuras do protagonista da série: Marcovaldo. Embora percebamos um contraste (uma tensão) entre a progressão temporal, os contos da obra e o retorno cíclico das estações, principalmente por cada um deles retratar uma estação do ano, não podemos afirmar que as histórias de Marcovaldo aconteçam em uma ordem necessariamente cronológica, já que a não-linearidade da narrativa é uma característica de muitas obras calvinianas. Caberia, pois, ao leitor tentar ele mesmo estabelecer entre as vinte histórias um nexo temporal e espacial.

A estruturação dessa sua obra em histórias ao mesmo tempo dependentes e independentes seria um dos motivos pelo qual o escritor italiano se realiza melhor na escritura do gênero conto, pois como ele próprio diz em sua obra póstuma Seis propostas para o próximo milênio: "meu temperamento me leva a realizar-me melhor em textos curtos - minha obra se compõe em sua maior parte de short stories" (1990, p. 61-62). Neste sentido, a nosso ver as histórias calvinianas tendem a se aproximar das narrativas orais que são a fonte da experiência em Benjamin, mas numa perspectiva moderna, em que o leitor ficaria, de certo modo, perdido, porque não haveria "experiência" que contextualizasse a narrativa.

Outro aspecto a ser pontuado sobre a obra em questão se refere ao fato de que Calvino, ao propor criar uma narrativa que retratasse a vida apressada, turbulenta dos grandes núcleos urbanos, concebe a sua obra com traços do neo-realismo, ao escrever, mesmo que alegórica ou humoristicamente, sobre as misérias da vida e as dificuldades ocasionadas pelo processo da modernização e industrialização. Tal premissa faz com que cheguemos a considerar, em consonância com o estudo de pesquisadores como Mario Barenghi e Claudio Milanini, que o livro Marcovaldo ovvero le stagioni in città encerraria a primeira fase de Calvino, já que nessa fase o escritor italiano adotaria como característica principal de suas obras o tema de denúncia ou de referência histórica como vemos em narrativas como $A$ trilha dos ninhos de aranha, que tem por enredo a Itália do pós-guerra, ou mesmo em obras como $O$ visconde partido ao meio, que, mesmo pendendo para o fantástico, procura denunciar - de forma alegórica - a crise do sujeito moderno que se sente muitas vezes dividido, fragmentado, deslocado, estrangeiro, partido ao meio.

Nessa perspectiva, consideramos que a obra Marcovaldo não é apenas um livro engraçado, cômico, pois evidenciamos que "um fundo de melancolia tinge o livro do começo ao fim. Poderíamos dizer que, para o autor, o esquema das historinhas cômicas é apenas o ponto de partida e que, ao desenvolvê-las, ele se entregou a uma sua veia lírica amarga e dolorida" (CALVINO, 1994, p. 140). Assim, embora os leitores possam se divertir com a leitura das aventuras/desventuras do senhor Marcovaldo, observamos a tentativa da obra de contrastar a busca pela natureza numa cidade grande. Daí consistiria a principal ironia desse livro: "Marcovaldo vai em busca da Natureza. Mas ainda existe a Natureza? A que encontra é uma Natureza ardilosa, falsificada, comprometida com a vida artificial" (CALVINO, 1994, p. 137). Calvino então não estaria se referindo a uma espécie de natureza reproduzida, disfarçada, sem aura?

No entanto, o propósito de Calvino não consiste simplesmente em relatar os problemas do homem contemporâneo nem em mostrar uma possível nostalgia em relação ao mundo

Cadernos Benjaminianos, n. 3, Belo Horizonte, jan.-jun. 2011, p.34-42 
natural perdido: o autor estabelece um lugar "no entre" para poder se expressar literariamente, entre o neo-realismo e o fantástico, entre o melancólico e o cômico:

As historinhas de Marcovaldo começam quando a grande onda neo-realista já sinaliza o refluxo; os temas que romances e filmes do pós-guerra ilustraram amplamente, tais como a vida da gente pobre que não sabe o que pôr na panela para o almoço e o jantar, correm o risco de se tornar lugares-comuns para a literatura, ainda que na realidade continuem amplamente atuais. $O$ autor experimenta então esse tipo de fábula moderna, de divagação cômicomelancólica à margem do neo-realismo. (CALVINO, 1994, p. 141-142)

Tal característica de Calvino de mascarar e mesclar a melancolia com o humor é recorrente entre os escritores italianos, pois como nos revela o próprio autor em "Traduzir é o verdadeiro modo de ler um texto"

os escritores italianos podem ensinar somente isto: a enfrentar a depressão, mal do nosso tempo, condição comum à humanidade do nosso tempo, defendendose com a ironia, com a transfiguração grotesca do espetáculo do mundo. Existem também os escritores que parecem transbordantes de vitalidade, mas é uma vitalidade com fundo triste, obscuro, dominada pela sensação da morte. É por isso que, conquanto seja difícil traduzir os italianos, vale a pena fazê-lo: porque vivemos com o máximo de alegria possível o desespero universal. Se o mundo é sempre mais insensato, a única coisa que podemos procurar fazer é dar-lhe um estilo ${ }^{2}$ (CALVINO, 2002, p. 91)

Isso é o que faz Calvino em Marcovaldo, uma obra que se recusa a oferecer ilusões. E é sob essa estratégia narrativa que o autor de As cidades invisiveis cria um personagem que sonha com a natureza, e que mesmo sendo adulto possui uma inocência infantil. Para descrevermos Marcovaldo, carregador de uma firma e pai de uma família numerosa, citamos a seguir um trecho retirado do conto "Cogumelos na cidade":

Esse Marcovaldo tinha um olho pouco adequado para a vida da cidade: avisos, semáforos, vitrines, letreiros luminosos, cartazes, por mais estudados que fossem para atrair a atenção, jamais detinham seu olhar, que parecia perder-se nas areias do deserto. Já uma folha amarelando num ramo, uma pequena que se deixasse prender numa telha, não lhe escapavam nunca: não havia mosca no dorso de um cavalo, buraco de cupim numa mesa, casca de figo se desfazendo na calçada que Marcovaldo não observasse e comentasse, descobrindo as mudanças da estação, seus desejos mais íntimos e as misérias de sua existência. (CALVINO, 1994, p. 7).

Enfatizemos também que Marcovaldo não consegue - ou não quer - compreender a linguagem da cidade que se expressa por meio de avisos, semáforos, vitrines, letreiros luminosos, cartazes. Ele se faz assim alheio à cidade industrializada, à modernidade acelerada.

Essa característica de Marcovaldo, como homem da natureza exilado, perdido na cidade, é retratada, por exemplo, na história "O tratamento com vespas", na qual, ao ler em um jornal que o veneno das abelhas curaria reumatismo, o personagem aplica o

Cadernos Benjaminianos, n. 3, Belo Horizonte, jan.-jun. 2011, p.34-42 
tratamento para isso confinando vespas em um vidro para que elas picassem as costas de seus pacientes. No entanto, como é comum nas histórias de Marcovaldo, o final é desastroso. Michelino, o filho do nosso herói desastrado, ao tentar capturar mais vespas, acaba atraindo-as para sua casa resultando num furioso ataque dos insetos. Assim, tanto Marcovaldo quanto todos os seus clientes acabam no corredor de um hospital irreconhecíveis pelo inchaço das picadas das abelhas. Como vemos, a comicidade ocorre por meio da inocência e ignorância dos personagens. Como sujeito deslocado da natureza, diferentemente do camponês sedentário, Marcovaldo fracassa em suas tentativas de ter experiências e fica com as "vivências", que, segundo Benjamin, entraram no lugar das experiências na modernidade.

Diferentemente do flâneur ocioso de Baudelaire, Marcovaldo trabalha numa fábrica, além de tentar vez ou outra outros meios de conseguir seu sustento. Em seu artigo "As representações urbanas em Marcovaldo ou as estações na cidade", Rogério Augusto Lima de Britto afirma que em Marcovaldo "nos deparamos com a fábrica em que o personagem Marcovaldo trabalha. Seu emprego é o símbolo de todos os outros empregos, de todas as grandes fábricas no seio da cidade, onde o ato de carregar e descarregar caixas infinitamente, fazer entregas, cumprir horários, etc., reina sobre todas as pessoas do nosso tempo" (LIMA DE BRITTO, p. 6). Observe-se que a fábrica da cidade de Marcovaldo era antes uma prisão abandonada. Nesse sentido, embora a função e o nome do local tenham se modificado, podemos considerar que lá o trabalho não liberta, mas sim continua aprisionando, escravizando os trabalhadores, numa atividade repetitiva, muito distante da atividade criadora e recriadora da Natureza. Também a cidade, assim como a fábrica, pode simbolizar todas as cidades grandes que sofrem e convivem com a modernidade e a industrialização.

Ainda considerando os contos dessa sua obra, Calvino observa, no posfácio da edição brasileira da Cia das Letras de 1994, que a estrutura narrativa adotada para a composição de Marcovaldo se assemelha à das histórias em quadrinhos das revistas infantis, sendo que ora os contos pendem para mais amargos e realísticos, ora neles prevalece o estado de alma e paisagem. O caráter de quadro, de imagem é fundamental para a questão tempo / espaço, pois fazem parte de uma substituição da progressão temporal (unidimensional) por formações espaciais (a imagem é uma formação bidimensional), que permitem estabelecer relações múltiplas entre si.

O conto "A marmita”, por exemplo, penderia para uma configuração mais amarga e realística uma vez que, ao almoçar a marmita que sua mulher Domitilla lhe preparara, Marcovaldo se depara com uma criança rica. Interessado na comida do carregador, o menino resolve trocar o seu almoço pelo de Marcovaldo; no entanto a governanta da casa, ao perceber o que acontecera, exigiu que a criança cuspisse a comida acusando Marcovaldo de ser um ladrão:

Marcovaldo se levantou, olhou ainda por um momento a fritada deixada pela metade, aproximou-se da janela, pousou prato e garfo no parapeito, fixou a governanta com desdém e se afastou. Ouviu a marmita rolar pela calçada, o choro do menino, a batida da janela que foi fechada com maus modos. Inclinou-se para recolher a marmita e a tampa. Estavam um pouco amassadas; a tampa não fechava bem. Enfiou tudo no bolso e foi para o trabalho. (CALVINO, 1994, p. 44)

Cadernos Benjaminianos, n. 3, Belo Horizonte, jan.-jun. 2011, p.34-42 
Como vemos, Calvino narra secamente esse acontecimento, mas a sensação de injustiça e de desigualdade flui durante a leitura já que tanto a figura de Marcovaldo é associada à de um ladrão, quanto a comida que alimenta o carregador não é considerada adequada à criança.

Já um conto que poderia revelar o estado de alma é "O coelho venenoso" ao destacar a solidão de um coelho. Nessa história, Marcovaldo se depara com um coelho preso em uma gaiola do hospital. Comovido com a solidão do animal, o nosso herói decide levá-lo para sua casa, mas lá Domitilla - sempre sem ter opção sobre o que fazer para se comer resolveu fazer carne de coelho. As crianças - para evitarem a morte do animal, o qual por sinal nunca parecia resistir, já que "nenhum animal parecia tão pouco afeito a uma fuga quanto aquele coelho" (CALVINO, 1994, p. 67) - o levaram embora. Enquanto isso, a polícia percorria a cidade para alertar que um coelho atacado por uma doença contagiosa grave havia sumido.

Nesse conto, podemos perceber que o coelho é símbolo da solidão. Tambéma família de Marcovaldo se encontra em situação semelhante, ora por não ter quase nunca o que comer, ora por não ter nunca a companhia de membros diferentes dos da família. Ao invés da vida em comum dos campos, a vida na cidade com suas multidões significa para a família de Marcovaldo paradoxalmente abandono e solidão.

Por suas andanças pela cidade, Marcovaldo pode ser considerado então como um tipo de flâneur que resiste à modernidade e ao ritmo acelerado da cidade. No entanto, se o flâneur de Baudelaire se sente em casa nas ruas, embora seja solitário, Marcovaldo flana pela cidade sem se sentir em casa, pois está sempre sem ou fora de lugar, uma vez que não consegue entrar no ritmo da modernidade acelerada. Assim, por exemplo, no conto "Lua e GNAC" as placas luminosas que ficavam piscando de trinta em trinta segundos o impedem de ver direto a luz da lua, como se a luz natural (da lua) competisse com a luz artificial. A placa luminosa que oferece alguma mercadoria para consumo compete, pois, com a lua, tomando-lhe o lugar.

Na cidade de Marcovaldo, a natureza aparece sempre em migalhas, artificializada, defeituosa, já que ela perdeu seu espaço para a industrialização e o crescimento urbano. Entretanto, o conto "O jardim dos gatos obstinados" revela que a natureza, embora já muito destruída, aparece como sinal de resistência. Uma cidade onde "as ruas são ininterruptamente percorridas pelo tráfego mortal dos carros trucidagatos; em cada metro de terreno onde se abria um jardim ou uma área livre ou as ruínas de uma velha demolição agora imperam condomínios, habitações populares, arranha-céus novos e faiscantes" (CALVINO, 1994, p. 115), mostra que não há mais espaço para a natureza. Mas, no entanto, uma chácara resiste a essa modernização: numa casa no centro da cidade vivem passarinhos, gatos, rãs e vários outros animais que resistem às investidas das grandes construtoras em destruírem esse espaço para erguerem mais arranha-céus, assim como fizeram com o resto da cidade.

A nosso ver, essa relação entre natureza e cidade em Calvino aparece num diálogo com Benjamin, pois ao passo que Benjamin faz tanto uma severa crítica à modernização, ao afirmar que ela teria causado a perda da aura (aura num sentido amplo, não só na arte mas a perda do caráter único), quanto uma apologia pois considera os novos aspectos que a modernização trouxe para as artes, em Calvino temos a tensão entre natureza e cidade ambiente urbano - uma vez que, embora critique também este aspecto negativo da modernização com o apagamento da memória das cidades e a destruição da natureza, ele não deixa de valorizar aspectos positivos da modernidade, transformando-os em matéria

Cadernos Benjaminianos, n. 3, Belo Horizonte, jan.-jun. 2011, p.34-42 
de invenção literária, de modo que alguns críticos o consideram um escritor da tecnologia, moderno.

Em Marcovaldo ou As estações na cidade Calvino não faz, pois, uma crítica somente à civilização industrial, mas também a qualquer nostalgia de "paraíso perdido", ou seja, o sentimento de um passado melhor e perdido. E é nesse sentido que percebemos uma crítica ao comportamento de Marcovaldo, aquele que vive de sonhos, numa ilusão, porque "o amor de Marcovaldo pela natureza é aquele que pode nascer apenas num homem da cidade; por isso não podemos saber nada da sua origem extra-urbana; esse estranho à cidade é o cidadão por excelência" (CALVINO, 1994, p. 141). Marcovaldo é, portanto, esse ser que não entende as linguagens da cidade, mas que tenta viver e sobreviver nela. Ele é como o vento, como mencionamos na epígrafe deste texto, pois se o vento vem de longe para a cidade, atravessando-a, tocando-a, Marcovaldo também vem de um outro lugar, é um ser estranho que flana pela cidade, buscando ao mesmo tempo sobreviver nela e a ela.

Talvez uma das muitas vias dessa instigante tensão tenha a ver com o fato de que o homem moderno queima fases, experiências, desconhecendo sua natureza formadora: a natureza com seus ciclos, com suas repetições de estações, mas sempre produzindo diferenças. Em geral, Calvino, ao invés de mostrar pura e simplesmente a destruição da natureza, a mostra ainda em vida, convivendo e lutando com a modernização em sinal de resistência. Baseando-nos, pois, nessa premissa, podemos constatar que, mesmo inerte ao ambiente urbano, Marcovaldo não é impedido de sonhar com a vida no campo. Se em "O narrador", o artesão ou o camponês sedentário podem desaparecer por causa da modernização, temos, em Marcovaldo ou As estações na cidade, um personagem, gerador de relatos e vivências, que resiste ao progresso, ao moderno, ao urbano.

Ao dialogar, conversar criticamente, narrativamente com Benjamin, Calvino deixa a lição conforme a qual por mais hostis que sejam as situações que se apresentem ao escritor, por mais que a modernidade simbolizada pela cidade industrializada persista em destruir e apagar as experiências e as memórias retirando ainda mais a aura das coisas, dos seres, o escritor tem que continuar resistindo com as suas essenciais ferramentas: as imagens, as palavras, os silêncios, o humor melancólico.

Abstract: At this essay, we aim to think about the relationship among the urban man, the nature and the new values initiated by Modernity as well as about the consequences of Modernization from some discussions raised by German Philosopher Walter Benjamin and from the literary text Marcovaldo or The seasons in the city (1963) by Italo Calvino.

Keywords: Modernity; Nature; City.

\section{Referências Bibliográficas}

BENJAMIN, Walter. A obra de arte na era de sua reprodutibilidade técnica. In: BENJAMIN, Walter. Magia e técnica, arte e política. Trad. Sergio Paulo Rouanet. São Paulo: Brasiliense, 1994. p. 165-196.

Cadernos Benjaminianos, n. 3, Belo Horizonte, jan.-jun. 2011, p.34-42 
BENJAMIN, Walter. O narrador. In: BENJAMIN, Walter. Magia e técnica, arte e politica. Trad. Sergio Paulo Rouanet. São Paulo: Brasiliense, 1994. p. 197-221.

BENJAMIN, Walter. Obras escolhidas volume 3: Charles Baudelaire, um lírico no auge do capitalismo. São Paulo: Brasiliense, 1995, pp 33-65. Trad. José Carlos Martins Barbosa e Hemerson Alves Baptista.

CALVINO, Italo. Marcovaldo ou As estações na cidade. Trad. Nilson Moulin. São Paulo: Companhia das Letras, 1994.

CALVINO, Italo. Seis propostas para o próximo milênio. Trad. Ivo Barroso. São Paulo: Cia. das Letras, 1990.

BRITTO, R. A. L. As representações urbanas em "Marcovaldo ou as estações na cidade". Revista Cientifica Semioses, v. 1, p. 1, 2006.

VELLOSO, Rita. Imagem dialética na cidade - sobre o trânsito de um conceito ao desenho do menos idealista dos objetos. Cadernos Benjaminianos, 2010. p. 1-8.

\section{Notas}

${ }^{1}$ Este trabalho foi escrito sob a orientação do Prof. Dr. Georg Otte (UFMG).

${ }^{2}$ Tradução de Andréia Guerini e Tânia Mara Moysés - Manuscrito. 